\title{
Formulating, Analyzing and Actualizing of Graduation Requirements for Food Science and Technology Major Based on OBE
}

\author{
WeiDong Wang ${ }^{1, a^{*}}$, Yue-e Sun ${ }^{1, b}$, Shuai Wang ${ }^{1, c}$, YiHui Chen ${ }^{2}$ \\ ${ }^{1}$ College of biological engineering, Xuzhou institute of technology, Xu Zhou, Jiang Su \\ ${ }^{2}$ Haitong food group Yuyao Co., Ltd. \\ awwd.123@163.com, bdreaming2002@1653.com, '398121585@qq.com
}

\section{Keywords: Graduation requirements; Professional certification; Outcome-based education}

\begin{abstract}
Specialty must have clear, open graduation requirements, which are required by engineering education professional certification standards. These graduation requirements should be able to support the achievement of training objectives. According to China engineering education accreditation standards (2015 Edition), the specific content of the twelve-professional certification in "graduation requirements" was analyzed and interpreted, which used food science and engineering specialty of Xuzhou university of technology as an example. Taking the case of "food safety" course, how to implement the graduation requirements through the syllabus is presented based on OBE. It not only has certain guidance and reference significance to the certification of food science and engineering, but also makes professional certification become the method and means to improve the quality of talent training.
\end{abstract}

\section{Introduction}

The Engineering Educational Professional Accreditation is a process that a professional accreditation institution (association) organizes the academic experts in the education circle and the technical experts in relevant industries of the engineering and technology field to evaluate and recognize the engineering education quality of relevant specialties in the engineering and technology field and propose improvement suggestions ${ }^{[1]}$.The professional accreditation has been carried out in many countries across the world, and its role in promoting the development of engineering education has also been proved to a large extent ${ }^{[2]}$. In June 2016, China joined the Washington Agreement, becoming a contract member of the Agreement, which marks the professional accreditation with the international substantive equivalence has kicked off in China. In order to improve the quality of the engineering education talent training, it is imperative to carry out the engineering education professional accreditation with international standards.

The professional accreditation follows three basic concepts: Outcomes-based Education (OBE), Student-centered Training and Continuous Improvement ${ }^{[2]}$. The core content of professional accreditation standards is to build an outcomes-based personnel training system, and carry on the continuous improvement. The outcomes-based education pattern is also known as the output-based, ability-based, goal-based or demand-based education, indicating the objective of teaching design and teaching implementation is that the students eventually obtain the learning outcomes through the educational process ${ }^{[3]}$. The learning outcomes herein refers to the maximum capacity that the students can have through a certain stage of learning, and the learning outcomes can in turn improve the original teaching design and teaching implementation through feedback. In the professional accreditation standards, the learning outcomes correspond to graduation requirements, and the graduation requirements support the realization of training objectives. In the school personnel training system, all teaching activities are completed around the graduation requirements. Based on the latest requirements of the China Engineering Education Accreditation Standard (Edition 2015),

\footnotetext{
* WeiDong Wang(1971-), male (Han), Ph.D., associate professor, mainly engaged in teaching of the food science and engineering specialty as well as the research on functional food ingredients and additives.
} 
this article studies how to develop and implement graduation requirements for the food science and engineering specialty, and makes a useful exploration to improve the accreditation level of the food science and engineering specialty in China.

\section{Development and Decomposition of Graduation Requirements}

\subsection{Principles to be followed when developing the graduation requirements}

The development of graduation requirements is the core link of the professional accreditation. The developed professional graduation requirements should focus on the formation of students' capacity, reflect the solution of complex engineering issues, and fully cover the 12 requirements of the National Accreditation General Standard for Engineering Specialized Education ${ }^{[4]}$. Different types of colleges have different training objectives, so all the graduation requirements developed for the specialty to be accredited must cover the 12 items of standards, and shall also reflect their professional features to support the training objectives.

\subsection{Decomposition of Graduation Requirements}

To make the developed graduation requirements play a guiding role in the training system, they must be decomposed into a number of measurable and evaluable index points with logical and professional features. Only in this way, can they guide teachers to carry out their targeted teaching, and students to perform their goal-oriented learning.

During the decomposition of graduation requirements, what should be first reflected is to train students' ability instead of knowledge. Therefore, more verbs should be used, such as "analyze" "control" "design" "express" "modeling" and so on, instead of the traditional "master ... ... knowledge"; and, secondly, the index points after decomposition should be measurable, evaluable and logical. For example, when decomposing the graduation requirement "3 design / develop solutions: Can design solutions for complex engineering issues, design systems, units (components) or processes meeting specific needs, and can reflect the innovation awareness in the design process, with the society, health, safety, law, culture and environment factors taken into account" in the accreditation standard, it may be conducted in the sequence of "determination the design goal, feasibility study, modeling calculation and design and submission of the report" which is the process to solve the engineering issues, and each index point shows a clear logical relationship.

\section{Graduation Requirements and Decomposition Index Points of the Food Science and Engineering Specialty}

Firstly, engineering knowledge: Master the mathematics and natural sciences engineering base knowledge and food expertise; and can use their theory and methods to solve the complex engineering issues in the food process design and food processing.

Decomposition index points: (1) Can apply the mathematics and natural sciences engineering base knowledge and food expertise to the description of complex food engineering issues; (2) Can establish appropriate mathematical models for food processing systems or processes, and can perform the solving process with appropriate specific conditions; (3) Can apply the engineering and food expertise to describe and distinguish the limits of food processing and optimization methods; and (4)Can apply the engineering and professional knowledge to the design, control and improvement of food processing.

Secondly, analysis of issues: Can apply the theoretical and technical methods of mathematics, natural sciences and engineering science to identify and describe the key issues affecting the food processing, food quality and food safety, and can analyze specific food engineering issues through literatures.

Decomposition index points: (1) Can identify and determine the key links and parameters of complex food engineering issues; (2) Can apply the basic principle to analyze the main factors 
affecting the food engineering issues; (3) Be aware of that there are multiple schemes to solve a probem, choose a reasonable solution through the literature research and describe the solution properly.

Thirdly, design / develop solutions: Can calculate and design the food factory, food unit operating equipment or systems and food processing flow; can carry out the development of new food products, propose solutions aiming to the factors affecting the food safety and can reflect innovation awareness in the design link, with the society, health, safety, law, culture and environment factors taken into account.

Decomposition index points: (1) Can determine the design objectives based on user demands and carry out the feasibility analysis on the design schemes through the economic evaluation under the safety, environment, law and other realistic constraints; (2) Can perform the process calculation and equipment design calculation through modeling; (3) Can integrate the food engineering unit operation process to perform the process flow design, and optimize and improve the design scheme, reflecting the innovation consciousness; and (4) Can design the product scheme according to the demands, with the society, health, safety, law, culture and environment factors considered in the scheme.

Fourthly, can use scientific methods to study the complex food engineering issues based on scientific principles, including designing experiments, analyzing and interpreting data, and obtaining reasonable and effective conclusions through information synthesis.

Decomposition index points: (1) Can analyze and study the raw materials, process flow and quality of finished products according to the factors affecting the food quality and safety; (2) Can choose appropriate study methods and technical routes to design the reasonable and feasible experiment scheme aiming to the factors having multiple impacts on the complex food engineering issues; (3) Can choose the experimental device and use scientific experimental methods to carry out food engineering related experiments safely; and (4) Can collect and collate the experimental data properly and carry on the correlation, modeling, analysis and explanation of the experimental results to obtain the reasonable and effective conclusion.

Fifthly, use of modern tools: Can develop, select and use appropriate technologies, resources, modern engineering tools and information technology tools for complex food engineering issues, including prediction and simulation of complex food engineering issues and can understand their limitations

Decomposition index points: (1) Can use the literature search tool to obtain effective information and resources via a variety of ways in food engineering activities; (2) Can choose the appropriate processing technology, process equipment and food safety control technology for complex food engineering issues, and understand its limitations; (3) Can use computer-aided design software AUTOCAD to design and plot the solutions for complex food engineering issues and understand its limitations.

Sixthly, engineering and society: Can conduct a reasonable analysis based on the engineering-related background, evaluate the effect of food engineering design, food processing and food resources development and utilization on the society, health, safety, law and culture; and can take reasonable methods and technical means to reduce or avoid their adverse effects.

Decomposition index points: (1) Have the experience in engineering internship and social practice; (2) Be familiar with the technical standards, intellectual property rights, industrial policies as well as laws and regulations related to the food professional field; (3) Can identify and analyze the potential effect of the development and application of new products, new technologies and new processes on the society, health, safety, law and culture, and can make an objective evaluation.

Seventhly, environment and sustainable development: Can understand and evaluate the effect of engineering practice aiming to complex engineering issues on the sustainable development of environment and society.

Decomposition index points: (1) Understand the connotation and significance of environmental protection and social sustainable development; (2) Be familiar with the policies and regulations 
related to environmental protection and sustainable development, and reflect the environmental protection and sustainable development when designing the food engineering schemes; and (3) Can evaluate the use efficiency of resources, "three wastes" disposal plan and safety precautions for complex food projects, and determine the potential risks that are harmful to human and environment in food production practice.

Eighthly, professional norms: Have humanity and social science accomplishments and social responsibility; can understand and comply with engineering ethics and norms in engineering practice, and fulfill their responsibilities

Decomposition index points: (1) Respect for life, care for others, uphold justice and keep integrity, with humanity knowledge, thinking ability and scientific spirit; (2) Understand socialist core values, know the national situation, safeguard national interests, and have a sense of responsibility to promote national nutrition and social progress; and (3) Understand the core concepts of engineering ethics, know the professional nature and responsibilities of food engineers, consciously abide by professional ethics and norms in engineering practice, and have legal consciousness.

Ninthly, individuals and team: Can undertake the responsibilities as an individual, team member and principal in a multidisciplinary team.

Decomposition index points: (1) Can actively cooperate with the team members with different backgrounds; can play the role of team member; and, (2) Have the ability to organize team members to work, and can synthesize the views of team members and make reasonable decisions.

Tenthly, communication: Can communicate with industry peers and the public effectively in terms of complex food engineering issues, including writing reports and designing manuscripts, presenting statements, clearly expressing or responding to directives. And have a certain international perspective, and can communicate and exchange ideas under the cross-cultural background.

Decomposition index points: (1) Can communicate and exchange ideas with industry peers and the public through oral, written, graphic, engineering terminology, etc.; (2) Have the basic ability to read and write in English, understand the international development trends of food engineering technology field, and can communicate and exchange ideas with others in the cross-cultural context.

Eeventhly, project management: Understand and master the food engineering management principles and economic decision-making methods, and can apply them in a multidisciplinary environment.

Decomposition index points: (1) Understand the importance of food engineering management and economic decision-making, and master the food engineering management principles and economic decision-making methods; and (2) Can analyze and solve the practical engineering issues like food development, food processing and food process optimization by applying the food engineering management principles and economic decision-making methods in a multidisciplinary environment.

Twelfthly, lifelong learning: Have the awareness of independent learning and lifelong learning and the capability of continuous learning to adapt to development.

Decomposition index points: (1) Have the awareness of independent learning and lifelong learning and recognize the necessity of continuous exploration and study; (2) Possess the knowledge foundation of lifelong learning, master the methods of independent learning, and has the ability to constantly learn and adapt to the development; and (3) Can choose appropriate methods to carry out independent learning according to personal or professional development needs, and maintain and enhance professional competence.

\section{Implementation of Graduation Requirements}

Take the graduation requirements as the standards to comprehensively evaluate the training quality baed on the OBE training system; and the curriculum system, teaching staff and schooling conditions and so on should be impemented around the core task, i.e. the formation of students' 
graduation capabilities $^{[5]}$. The decomposition of graduation requirements index points plays a guiding role in the curriculum system design of training program, development and implementation of curriculum syllabus, setting of curriculum objectives, as well as the design of curriculum teaching plans and teaching outlines, teaching method reform and learning outcomes assessment contents $^{[6]}$. Therefore, optimizing the curriculum system supporting the graduation requirements and estalishing the corresponding relationship between teaching activities and graduation requirements are critical to implement the graduation requirements.

\subsection{Establishment of correlation matrix for the curriculum system and graduation requirements}

The curriculum system is the cornerstone supporting graduation requirements, and the realization of graduation requirements depends on the implementation of the curriculum system. After the graduation requirements are developed, arrange specialty principals, the director of teaching and research section, curriculum principals and backbone teachers to set the curriculum system of the appropriate specialty according to the decomposed graduation requirements index points, determine the supporting curriculum of the index points (usually 3 to 5 curriculums), and assign values to each curriculum in terms of supporting strength. The sum of support weight is 1 . Ensure that each decomposition index point is covered by the curriculum and the teaching contents and process of the curriculum can provide support for the realization of the appropriate graduation requirement. Set the correlation matrix according to the degree of correlation between the teaching contents and the index points of each curriculum, and determine the support strength of different curriculums (strong support: $\mathrm{H}$, medium support: $\mathrm{M}$, weak support: L) (see Table 1 ).

Through the establishment of a correlation matrix, we can determine whether the curriculum system is reasonable, whether a curriculum should be set up and which curriculum should be constructed as the focus.

Table 1 Correlation Matrix of Engineering Practice, Graduation Design (Thesis) and Graduation Requirements

\begin{tabular}{|c|c|c|c|c|c|c|c|c|c|c|c|c|}
\hline Curriculum & \begin{tabular}{|l|} 
Engineering \\
Knowledge
\end{tabular} & $\begin{array}{l}\text { Problem } \\
\text { Analysis }\end{array}$ & $\begin{array}{l}\text { Design/ } \\
\text { Develop } \\
\text { Solutions }\end{array}$ & Research & $\begin{array}{c}\text { Use of } \\
\text { modern tools }\end{array}$ & \begin{tabular}{|l|} 
Engineering \\
and Society
\end{tabular} & $\begin{array}{l}\text { Environment and } \\
\text { Sustainable } \\
\text { Development }\end{array}$ & $\begin{array}{c}\text { Professional } \\
\text { Norms }\end{array}$ & $\begin{array}{c}\text { Individuals and } \\
\text { Team }\end{array}$ & $\begin{array}{c}\text { Communica } \\
\text { tion }\end{array}$ & $\begin{array}{c}\text { Project } \\
\text { Management }\end{array}$ & $\begin{array}{l}\text { Lifelong } \\
\text { Leaming }\end{array}$ \\
\hline $\begin{array}{l}\text { Experimentof Food } \\
\text { Engineering Principles }\end{array}$ & & & & L & & & & & & & & \\
\hline $\begin{array}{l}\text { Curriculum Design of } \\
\text { Food Engineering } \\
\text { Principles }\end{array}$ & M & L & $\mathrm{H}$ & & $\mathrm{H}$ & & & & & & M & \\
\hline $\begin{array}{l}\text { Comprehensive } \\
\text { experiment of food } \\
\text { process }\end{array}$ & L & L & & L & & & & M & L & & & \\
\hline $\begin{array}{l}\text { Production } \\
\text { recognization practice }\end{array}$ & & & & & & $\mathrm{H}$ & M & M & M & & & \\
\hline $\begin{array}{l}\text { Professional } \\
\text { comprehensive } \\
\text { training and practice }\end{array}$ & & L & & M & L & & M & & $\mathrm{M}$ & M & & L \\
\hline Graduation Practice & & & $\mathrm{L}$ & & & $\mathrm{H}$ & $\mathrm{H}$ & $\mathrm{H}$ & $\mathrm{L}$ & $\mathrm{H}$ & & \\
\hline $\begin{array}{l}\text { Graduation Design } \\
\text { (thesis) }\end{array}$ & & & M & $\mathrm{L}$ & & & M & $\mathrm{L}$ & & $\mathrm{H}$ & $\mathrm{H}$ & M \\
\hline
\end{tabular}

\subsection{Development and Implementation of Curriculum Syllabus}

The syllabus is the rules not only regulating teachers' teaching behaviors, but also guiding students in their learning behaviors. The professional accreditation puts foward the definite requirements on the syllabus, namely the syllabus should clearly defined "1) The curriculum objectives of the curriculum; 2) The corresponding relationship between curriculum objectives and related graduation requirements index points; 3) ; The corresponding relationship between curriculum objectives and teaching contents and teaching methods; and 4)VCurriculum assessment methods. Therefore, the curriculum objectives, teaching contents and teaching methods as well as assessment methods are all realized around the graduation requirements based on OBE. 


\subsubsection{Setting of Curriculum Objectives}

With the Food Safety Science as an example, the traditional syllabus describes the curriculum objectives as " Students should meet following requirements through the study this curriculum: 1 . Understand the concept of food safety, hazards in food processing, types of mycotoxins, types of environmental pollution, types of chemical substances and natural toxic substances in animals and plants; 2. Be familiar with the corruption phenomenon of various types of food, characteristics of mycotoxin toxication, sources of various pollutions and safety issues of commonly-used packaging materials. 3. Master the control measures of food corruption, the toxicity of mycotoxins, the impact of environmental pollution on food safety, the safety of chemical substances, the impact of biological pollution on food safety, the safety of non-thermal sterilization food, the safety of genetically-modified foods (Supporting graduation requirements 3, 5 and 6) ".

OBE-based curriculum objectives can be set as follows: After studying this curriculum, students should have the following capabilities 1 . Can identify the risk factors in the product development, process design and other food engineering practice, and analyze the food safety based on the scheme (supporting graduation requirement 3); 2. Can design solutions for food safety, choose a reasonable food safety control technology (supporting graduation requirement 5); 3 . Be familiar with food safety-related laws and regulations; can objectively evaluate the efffects of new food products, new technologies and new processes on the food safety (supporting graduation requirement 6).

\subsubsection{Determination of Teaching Contents and Teaching Methods for the Curriculum}

Table 2 lists the teaching contents and teaching methods corresponds to curriculum objective 1 of the curriculum Food safety Science. When setting the teaching contents and teaching methods, ensure the teaching contents correspond to the curriculum objectives and the teaching methods support the realization of the curriculum objectives.

Table 2 Teaching Contents and Teaching Methods of Curriculum Objectives

\begin{tabular}{|c|c|c|c|}
\hline $\begin{array}{c}\text { Curriculum } \\
\text { Objectives } 2\end{array}$ & $\begin{array}{c}\text { Graduation Requirement } \\
5 \text { - index points }\end{array}$ & Teaching Contents & $\begin{array}{l}\text { Teaching } \\
\text { Methods }\end{array}$ \\
\hline $\begin{array}{lr}\text { Can } & \text { design } \\
\text { solutions for the } \\
\text { food safety and } \\
\text { choose }\end{array}$ & $\begin{array}{l}\text { 5.2 Can choose the } \\
\text { appropriate processing } \\
\text { technology and the } \\
\text { process equipment and } \\
\text { food safety control } \\
\text { technology for complex } \\
\text { food engineering issues, } \\
\text { and understand their } \\
\text { limitation. }\end{array}$ & $\begin{array}{lr}\text { (1) Safety of food } \\
\text { processing technology } \\
\text { (2) Food safety control } \\
\text { systems HACCP and } \\
\text { ISO22000 } \\
\text { (3) Food traceability system }\end{array}$ & $\begin{array}{l}\text { (1) Classroom } \\
\text { teaching } \\
\text { (2) Case } \\
\text { analysis } \\
\text { (3) Design } \\
\text { training of food } \\
\text { safety system }\end{array}$ \\
\hline
\end{tabular}

\subsubsection{Determination of Curriculum Assessment Methods}

The curriculum assessment methods should be clearly determined in the syllabus. Design the corresponding learning tasks and scoring standards according to the graduation requirement supported by curriculum objectives, to assess students' learning outcomes. Learning tasks may be examinations, assignments, essays, experiments, etc. The above learning tasks are also arranged in the traditional syllabus, but they are based on teachers' interest, not purposing to assess students' learning outcomes. Develop the scoring standards for the assessment methods and distribute them to students along with the syllabus, so that they can play a guiding role and each student knows what their learning objectives are, and what capabilities they have. 
Table 3 Assessment Method of Course Objectives

\begin{tabular}{|l|l|l|}
\hline \multicolumn{1}{|c|}{ Course Objectives } & \multicolumn{1}{|c|}{ Assessment Content } & \multicolumn{1}{c|}{$\begin{array}{c}\text { Learning Task / } \\
\text { Assessment Method }\end{array}$} \\
\hline $\begin{array}{l}\text { 1. Can identify the risk factors in the product } \\
\text { development, process design and other food engineering } \\
\text { practice, and analyze the food safety based on the } \\
\text { scheme (supporting graduation requirement 3) }\end{array}$ & $\begin{array}{l}\text { Ability to identify food } \\
\text { hazards }\end{array}$ & $\begin{array}{l}\text { Examination } \\
\text { investigation report }\end{array}$ \\
\hline $\begin{array}{l}\text { 2. Can design solutions for food safety, choose a } \\
\text { reasonable food safety control technology (supporting } \\
\text { graduation requirement 5) }\end{array}$ & $\begin{array}{l}\text { Food safety system design } \\
\text { capability }\end{array}$ & $\begin{array}{l}\text { Design } \\
\text { examination }\end{array}$ \\
\hline $\begin{array}{l}\text { 3. Be familiar with food safety-related laws and } \\
\text { regulations; can objectively evaluate the efffects of new } \\
\text { food products, new technologies and new processes on } \\
\text { the food safety (supporting graduation requirement 6) }\end{array}$ & $\begin{array}{l}\text { Food safety-related laws } \\
\text { and regulations } \\
\text { Safety of non-thermal } \\
\text { sterilization food and } \\
\text { genetically-modified food }\end{array}$ & $\begin{array}{l}\text { Classroom } \\
\text { examination } \\
\text { homework }\end{array}$ \\
\hline
\end{tabular}

\section{Conclusion}

The implementation of engineering education professional accreditation contributes to improving the quality of teaching and training the talents that are urgently needed and have the capability to solve complex engineering issues in the indusrty. In the accreditation, be sure to follow the OBE concept, develop reasonable graduation requirements and decompose the same so that the graduation requirements play the guiding role. When decomposing the graduation requirements, combine the specialty characteristics and include the capabilities that are needed by the society and industry in the index points. What's more critical is to implement the graduation requirements, define the curriculum objectives and graduation requirements, teaching content and methods as well as the curriculum assessment relationship through the development of syllabus. Only when the syllabus becomes the standards for teacher's teaching and students' learning, can the accreditation really play a role, and can the students pass the accreditation.

\section{Acknowledgments}

Fund Project: Project of “Six Talent Peak” in Jiangsu Province (NY-167).

\section{References}

[1] Lin Jian. Accreditation, Reformation and Development of Engineering Education Research in Higher Education of Engineering [J] Higher Education Engineering Research, 2015 (2): 10-19.

[2] Li Zhiyi. Analytical engineering education professional certification results oriented concept [J]. China Higher Education, 2014 (17): 7-10.

[3] Wu Qiufeng, Li Hongxia and Shen Yang. Research on the higher engineering teaching reform based on OBE perspective [Jl. Education Exploration, 2016 COS): 97-100.

[4] China Engineering Education Accreditation Association. General Standards for Engineering Education Professional Accreditation[EB / OL]. 2016, http: //cn.ceeaa.org.cn/index.php.

[5] Li Zhiyi. Promotion of engineering education and teaching reform adapting to the requirements of accreditation [J] China University Teaching, 2014 (6) : 9-16.

[6] Li Xiaoming, Shi Ruiqian, Zou Chong, et al. Curriculum System Optimization of the Metallurgical Engineering Specialty Based on Graduation Requirement [J]. China Metallurgical Education, 2017 (1): 78-81. 